\title{
Interactive comment on "Calving event size measurements and statistics of Eqip Sermia, Greenland, from terrestrial radar interferometry" by Andrea Walter et al.
}

\section{Surui Xie (Referee)}

suruixie@mail.usf.edu

Received and published: 29 May 2019

\section{Summary:}

This manuscript presents detailed observations of the glacier front of Eqip Seria, Greenland with terrestrial radar interferometry (TRI). Digital elevation models were derived from TRI measurements and used to generate calving event data. By analyzing calving event numbers/sizes and their temporal and spatial distributions, the authors concluded that the deep and shallow water sectors of the glacier front have different calving statistics and styles: 1) In the deep water sector (70-100 m), TRI observed calving events are less frequent, calved icebergs are smaller and the sizes follow a 
power law distribution. Subaquatic calving is prominent here, combined with oceanic melt, they contribute up to $75 \%$ of the frontal mass loss. 2) In the shallow water sector $(0-20 \mathrm{~m})$, TRI observed calving events are more frequent, with much larger ice blocks (single volume larger than $5 \times 10^{\wedge} 4 \mathrm{~m}^{\wedge} 3$ ) occasionally calved, and the sizes of all calved volumes follow a log-normal model. Several possible reasons for the different characteristics in observed surface calving events were discussed, including subsurface melt, subaqueous calving, cliff height and shape, and bed topography. The authors concluded that subsurface melt and calving are the major contributors to mass loss in the deep water sector, but are trivial in the shallow water sectors. On the other hand, an inclined front geometry at the shallow water sectors results in a thicker and stable ice cliff, allowing larger potential ice volumes to calve. Besides, a rock ridge at the shallow water sectors caused less frequent but much larger calving events. In addition, several other types of data (i.e., air temperature, shortwave radiation and tide) were presented but no relationship with calving was established.

The manuscript is well organized, overall well written but can be improved. The topic meets the scope of The Cryosphere, the techniques of TRI and pressure sensor are suitable for this type of study, the references are appropriate. However, I do not think the current manuscript is suitable for publication in The Cryosphere. Below I list some major problems in the data analysis and interpretation. I encourage the authors to address these questions and consider a resubmission.

Major comments:

1) Uncertainty in TRI derived elevation models needs better assessment. The authors randomly choose 30 DEMs and computed the variability (its definition needs to be provided in the manuscript, please see my detailed comments) as a measure of the precision. Although the mean variability is $1 \mathrm{~m}$, but the maximum variability is 5 $\mathrm{m}$. Therefore, the DEMs are likely to have an uncertainty of $\sim 1 \mathrm{~m}$ to several meters. Although a threshold of $5 \mathrm{~m}$ elevation decrease between adjacent DEMs is used to determine calving events, but note that even among only 30 DEMs there is a variability of

Printer-friendly version

Discussion paper
Interactive comment

C2 
$5 \mathrm{~m}$ between two DEMs. The calving statistics of this manuscript come from hundreds of DEMs, several large random errors (2-sigma or above) or outliers can significantly change the results. I suggest the authors to provide more details on error analysis.

2) Based on the calving data derived from TRI elevations, the authors concluded that surface calving is more frequent in the shallow water sectors, and the sizes are generally larger. This seems apparent if just looking at Figure 5c. However, due to lack of rigorous uncertainty analysis, I think this conclusion is hasty and may be flawed. In general, noise in TRI measurements increases with distance, and can increase rapidly at a distance of 4-6 km. Glacier front on the northwestern section (shallow water sectors in this manuscript) is further from the radar than the southeastern section (deep water sector), thus radar data on the northwestern section of the glacier should be noisier if all other conditions are similar. Besides, the northwestern section of the glacier front is crevassed heavier than the southeastern section (Figure 1), and elevation changes rapidly (inclined at a slope of 50 degrees according to the authors), both are more likely to induce phase unwrapping errors than a flat and less crevassed surface. These (i.e., increased noise with distance, phase unwrapping problems) could be some of the reasons why the identified calving volumes are more variable and the cumulative calving volumes are larger along the SL/SM/SR/M sectors. In Figure 5c, timing and sizes of calving events at different distances look random, but considering the characteristics of radar noise, it is important to examine if the observed pattern is due to noise or unwrapping errors. Here I suggest one possible method to test how much noise affected the distribution pattern in calving events: using the same analysis approach as presented in the manuscript, but apart from calculating calving volume based on pixels whose elevation decreased by $>5 \mathrm{~m}$, the authors can also calculate "increased volumes" by pixels whose elevations increased by $>5 \mathrm{~m}$. If a similar distribution pattern as in Figure $5 c$ is seen, then the derived "calving volumes" are likely disturbed. The authors can probably add a plot of such "increased volumes" to the negative side of $y$-axis in Figure $5 d$ (can used light blue color if the authors don't want it be distracting). A comparison figure of "detected increasing volume" similar as Figure $5 \mathrm{c}$ can also add

Interactive comment
Printer-friendly version

Discussion paper 
important information to the manuscript, and it can go to the supplement if the authors would like to save space in the main manuscript.

3) According to the manuscript, there was very little surface calving observed by TRI at sector $D$ (the deep water sector), and mass loss due to subaqueous calving is dominant $(50 \%$ or more, depends on the rate of oceanic melt) here. Limited evidence of subaqueous calving was shown in the manuscript. Even if substantial subaqueous calving events occurred and contributed significantly to the mass loss at the deep water sector, the manuscript failed to explain where the mass goes. I also think it is not adequate to simply assume that subaqueous calving is independent of TRI observed surface calving. If subaqueous calving would not cause surface elevation change by following the authors' logic, then what was there to fill the space left by the "subaqueous calving"? Besides, if TRI observed little calving at sector D, then glacier front at this section should advance, especially at the high velocity area. Speed in the middle of this sector is $16 \mathrm{~m} /$ day, in $\sim 7.65$ days, ice front here can advance over 100 meters, much larger than the resolution of either Landsat/Sentinel satellites or TRI images so should be detectable. However, Supplementary Figure S1 rejected this.

4) The manuscript did not explain the method they used to choose the study area for calving detection well. Although on page 6 the authors mentioned that they applied a mask with $\sim 150 \mathrm{~m}$ wide across the glacier front, however, the glacier front was constantly moving, so a Lagrangian frame should be used. Whatever the reference frame was, according to the methods presented by the authors, areas with calving event detected (Figure 4) over the center of sector D should have the largest alongflow direction width. This is because glacier front at this location should advance (also see comment above), thus the test area should move. Whereas Figure 4 shows a different pattern.

Printer-friendly version

I think the above comments can already warrant a rejection or resubmission. There are also many other problems with the current manuscript, such as inconsistent numbers and unjustified assumptions. However, I do believe that the authors are working 
towards the right direction. Hopefully these comments can help.

Sincerely,

-Surui Xie

I attach detailed comments as a supplementary file.

Interactive

comment

Please also note the supplement to this comment:

https://www.the-cryosphere-discuss.net/tc-2019-102/tc-2019-102-RC1-

supplement.pdf

Interactive comment on The Cryosphere Discuss., https://doi.org/10.5194/tc-2019-102, 2019. 